\title{
Shear thickening, temporal shear oscillations, and degradation of dilute equimolar CTAB/NaSal wormlike solutions
}

Journal Article

Author(s):

Lutz-Bueno, Viviane; Kohlbrecher, Joachim; Fischer, Peter

Publication date:

2013-04

Permanent link:

https://doi.org/10.3929/ethz-b-000068229

Rights / license:

In Copyright - Non-Commercial Use Permitted

Originally published in:

Rheologica Acta 52(4), https://doi.org/10.1007/s00397-012-0672-4 


\title{
Shear thickening, temporal shear oscillations, and degradation of dilute equimolar CTAB/NaSal wormlike solutions
}

\author{
Viviane Lutz-Bueno • Joachim Kohlbrecher • \\ Peter Fischer
}

Received: 24 September 2012 / Revised: 16 December 2012 / Accepted: 20 December 2012 / Published online: 27 January 2013

(C) Springer-Verlag Berlin Heidelberg 2013

\begin{abstract}
The rheological characterization of dilute and semi-dilute equimolar cetyltrimethylammonium bromide and sodium salicylate solutions is reported, including their linear and nonlinear responses. Start-up experiments and direct birefringence measurements suggest that even at a concentration of as low as $1.0 \mathrm{mM}$, temporal shear oscillations occur at low shear rates. At concentrations above $10 \mathrm{mM}$, those low-stress structures vanish and give way to shear-thickening and shear-banding behaviors as seen for other semi-dilute surfactant solutions. Also, the degradation of these solutions after exposure to rubber pump tubing is covered.
\end{abstract}

Keywords Viscoelastic surfactant solution .

Nonlinear shear - Gradient banding · Wormlike micelles .

Temporal shear oscillation $\cdot$ Micellar degradation

Surfactant molecules in aqueous solution aggregate into micelles of diverse shapes and ordering. Such self-assembly minimizes the free energy of the system by removing the hydrophobic tails from contact with water. Once inside the micelles, the tails are subjected to packing constraints and form a hydrocarbon core with liquidlike behavior. Thus, the residual water/tail contact points become responsible

V. Lutz-Bueno · P. Fischer $(\bowtie)$ Institute of Food, Nutrition and Health, ETH Zurich, Schmelzbergstrasse 9, 8092 Zurich, Switzerland

e-mail: peter.fischer@hest.ethz.ch

V. Lutz-Bueno $\cdot$ J. Kohlbrecher

Paul Scherrer Institute, Laboratory of Neutron Scattering, 5234 Villigen, Switzerland for the micelle growth in length by interacting with other short chains. The finite size of the micelles is defined by the head groups' steric and electrostatic repulsions, which try to maximize the surface energy of the micelle. Micellar growth is also entropically favorable, since many small spherical micelles have higher entropy than fewer wormlike or rodlike ones. The resulting micelle is held together by weak physical interactions, which allow them to break and reform with time. Wormlike micellar solutions are known as living polymers, since they can break into smaller micelles with residual charge and also regenerate larger micelles (Cates 1987; Cates and Candau 1990). The rheological behavior of these wormlike aggregates is analogous to that of polymer molecules in solution, with the additional feature that the micelles have a limited lifetime. Cates and Candau (1990) showed that the relaxation time of the solution is Maxwellian and depends on the timescale of reptation and breaking regime of the micelles $\left(\lambda_{\text {break }} \ll \lambda_{\text {rep }}\right)$. Besides fundamental interest in the flow behavior, the intense research (see overview by Ezrahi et al. (2006)) on surfactant/salt systems over several decades has been driven by applications such as alveolar function model (Russel et al. 1989), templates for microstructured materials (Kim and Yang 2000), drug delivery (Goymann 2004), solar energy storage (Vasudevan et al. 2008), enhanced oil recovery and turbulent drag reduction (Hadri and Guillou 2010). For material characterization, many methods were employed such as rheology, NMR microscopy (Britton and Callaghan 1997, 1999), ultrasound velocimetry (Herle et al. 2008; Fischer et al. 2009), particle image velocimetry (Miller and Rothstein 2007; Helgeson et al. 2009a), light scattering measurements (Liu and Pine 1996; Prötzl and Springer 1997; Hu et al. 1998a, b; Kim and Yang 2000), small-angle neutron scattering (Kalus et al. 1989; Hofmann et al. 1991; Herle et al. 2007; Helgeson et al. 2009a), and 
flow and electric birefringence (Rehage et al. 1986; Hofmann 1991; Hu et al. 1993a, b, 1994; Azzouzi et al. 2005; Miller and Rothstein 2007; Helgeson et al. 2009a).

One widely studied surfactant is cetyltrimethylammonium bromide (CTAB), which in water aggregates into wormlike micelles above the critical micelle concentration of $0.9 \mathrm{mM}$ at $25 \pm 1{ }^{\circ} \mathrm{C}$ (Israelachvili 1985). For concentrations higher than $300 \mathrm{mM}$ of CTAB, the wormlike micelles grow until the persistence length leads to entanglements and to complex viscoelastic behavior (Hu et al. 1994). This surfactant solution also exhibit a hexagonal liquid crystal phase at concentrations higher than $700 \mathrm{mM}$ (Mohanty et al. 2001). Viscoelasticity can also develop at diluted concentration regimes without going through the spherical micelle phase when salts such as sodium bromide ( $\mathrm{NaBr}$ ) or sodium salicylate (NaSal) are added to the system. The interaction with counterions from the salt causes growth in length, since the counterions bind strongly due to electronegativity difference, which screens electrostatic interactions (Hartmann and Cressely 1997a, b; Shikata et al. 1987; Kim and Yang 2000). For the $\mathrm{CTAB} / \mathrm{NaBr}$ system, the $\mathrm{Br}^{-}$anions of the surfactant and salt form a double layer on the surface of the micelle without penetrating into it (Lin et al. 2003). NaSal inserts salicylate ions $\left(\mathrm{Sal}^{-}\right)$into the micelle core, breaking the screening shell (Mohanty et al. 2001) and decreasing the electrostatic repulsion between the head groups and thereby promoting the formation of longer wormlike micelles $(\mathrm{Hu}$ et al. 1994). The presence of salt also promotes a uniform length for the chains, which contrasts with the polydisperse size of neutral micelles. Ten millimolars was defined as the boundary between the dilute (micrometric linear chains) and semi-dilute solutions (when the chains start to entangle and a three-dimensional network is formed).

The rheological behavior of CTAB solutions has been widely investigated. Specific rheological properties or microstructures can be achieved through the use of various additives. The most important parameter, as mentioned in the previous paragraph, is the ratio between the concentration of salt $C_{\mathrm{s}}$ and concentration of surfactant $C$ in aqueous solution (known as molar ratio $[\mathrm{NaSal}] /[\mathrm{CTAB}]=\frac{C_{\mathrm{s}}}{C}$ ) which defines the size, shape, and organization of micelles. Hartmann and Cressely (1997a) demonstrated that when $\frac{C_{\mathrm{s}}}{C}<0.25$, the zero-shear viscosity $\eta_{0}$ is similar to the viscosity of pure water $\left(8.9 \times 10^{-4} \mathrm{~Pa}\right.$ s at $\left.24^{\circ} \mathrm{C}\right)$, since at low concentration, the wormlike micelles are separated by distances greater than the micellar size. In general, at $C_{\mathrm{s}}<C$, the low concentration of the salt dissociates its molecules into ions. The anions $\left(\mathrm{Sal}^{-}\right)$are attracted by the cationic surface (head group) of the micelle, binding strongly and being partly adsorbed as carboxylic groups sticking outwards from the micelle axis (Shikata et al. 1988). If $C_{\mathrm{s}}>C$, the excess of $\mathrm{Sal}^{-}$ions reduces the zero-shear viscosity of the solution (Rehage and Hoffmann 1991; Fischer and Rehage 1997). It makes the breakdown process of the micelles faster than their recombination with the $\mathrm{Sal}^{-}$ions, which affects the lifetime and length of the micelles (Shikata et al. 1989; Kim and Yang 2000). In case of a large excess of salt, the wormlike micelles break up or become spherical again. If the amount of NaSal molecules in the solution exceeds the number of surfactant molecules, the micellar breakage rate increases, decreasing the lifetime of the micelles. In both cases, they become shorter and more compact, decreasing again the zero-shear viscosity. If $\frac{C_{\mathrm{s}}}{C}$ is about unity, long wormlike micelles with longer lifetimes and more uniform size distribution are formed (Hu et al. 1994; Hartmann and Cressely 1997a).

In flow curves of equimolar surfactant/salt solutions, a critical shear rate $\dot{\gamma}_{\mathrm{c}}$ characterizes the transition from Newtonian to nonlinear flow domains, i.e., shear thinning or thickening plus the presence of shear bands. The transition into the non-Newtonian flow regime can be gradual or abrupt and depends primarily on the concentration and concentration ratio of both surfactant and salt. For $\dot{\gamma}>\dot{\gamma}_{\mathrm{c}}$, shear-banding structures can form showing high and low shear rate regions. These flow regions result in complex transient and spatial flow patterns (Hartmann and Cressely 1997a; Britton and Callaghan 1997, 1999; Herle et al. 2005, 2007). Two kinds of banding mechanisms were proposed: velocity (gradient) banding and vorticity banding (Fischer et al. 2002; Aradian and Cates 2006; Dhont and Briels 2008; Olmsted 2008). The complex nature of the intrinsically coupled flow and morphology, i.e., nonstationary macroscopic properties, which fluctuate with time (Hu et al. 1993b), make their rheological response a challenging field of study.

Equimolar dilute $\mathrm{CTAB} / \mathrm{NaSal}$ solutions' shear thickens by the formation of shear-induced structures (Hu et al. 1993b). Liu and Pine (1996) investigated diluted equimolar $\mathrm{CTAB} / \mathrm{NaSal}$ solutions with small-angle light scattering in Couette flow. The authors reported that bands were formed at the inner and outer walls of the gap. With increasing shear rate, the bands become unstable, growing and retracting as fingerlike structures from the inner cylinder (stationary in that experiment) spaced at distances inversely proportional to the concentration. Those structures give rise to the shear thickening and to fluctuations in rate/stress (called shearinduced gelation). Miller and Rothstein (2007) report multiple high shear bands on the inner moving wall of a Couette cell. For higher concentrations, Helgeson et al. (2009a) suggested that for a $490 \mathrm{mM} \mathrm{CTAB}$ solution (without salt), the shear bands result from a nonequilibrium shear-induced separation into a micellar phase in the low shear band and the flow-aligned paranematic state in the high shear band. This transition happens when critical values of segmental orientation and alignment are achieved. The same authorstudied 
the shear banding over a range of temperatures and concentrations in order to build a nonequilibrium state diagram from which an order parameter for the system can be estimated (Helgeson et al. 2009b). These observations are in line with earlier studies by Rehage et al. (1986), who proposed the formation of supramolecular micelles, and by Hofmann et al. (1991), who suggested arrangements of the micelles in nematic domains.

In this paper, the main objective was to analyze the rheological behavior of dilute and semi-dilute equimolar solutions of CTAB/NaSal under different flow conditions such as geometry and gap size. The rheological properties, in particular the formation of low-concentration shear bands, are supported by morphological studies utilizing a direct birefringence setup. Considering the use of these solutions, the degradation of the viscoelastic properties of the sample is of importance. The destruction of the wormlike micelles is investigated under mechanical load and solubilization of polymers/plasticizers. The manuscript is organized as follows: In Section "Experimental," the materials, experimental setup, and studied parameters are discussed briefly. Results for rheometry, direct flow birefringence, degradation, and small-angle neutron scattering (SANS) experiments are presented and discussed in Section "Results and discussion" before presenting a brief summary.

\section{Experimental}

\section{Materials}

$\mathrm{CTAB}$ and NaSal were obtained from Fluka (Buchs, Switzerland) and used without further purification. CTAB is a cationic surfactant, while NaSal is an organic salt whose anion can bond to micelles. Both compounds will also lead to the formation of $\mathrm{NaBr}$ in aqueous solution.

Required amounts of surfactant and salt were weighed in order to prepare aqueous solutions with equimolar concentrations between 1 and $100 \mathrm{mM}$. The powders were dissolved into $100 \mathrm{ml}$ of Millipore water and mechanically stirred for at least $4 \mathrm{~h}$ to guarantee homogeneity. Afterward, the system was maintained at rest for at least $48 \mathrm{~h}$ to recover its properties, since due to stirring foam formation was observed. Aged solutions (6 months old) were compared to the freshly prepared ones, and they showed the same rheological behavior, assuring that there is no degradation due to storage or light incidence on the solution.

\section{Rheology}

The rheological properties were investigated with a stresscontrolled rheometer (Rheometric Scientific DSR) equipped with Couette geometry (inner cylinder diameter varying between $d_{\mathrm{i}}=29.5,27,24.5$, and $22 \mathrm{~mm}$, outer cylinder diameter constant on $d_{\mathrm{o}}=32$ or $30.5 \mathrm{~mm}$, inner cylinder height $h=44.4 \mathrm{~mm}$ ), parallel-plate geometry (diameter $40 \mathrm{~mm}$ ), and cone-plate geometry (diameter $40 \mathrm{~mm}$ and cone angle $0.04 \mathrm{rad}$ ). The inner cylinders have an air reservoir at the bottom, which essentially transfers no torque to the fluid during rotation. The range of shear stresses used was from $10^{-3}$ to $20 \mathrm{~Pa}$, depending on the concentration of the solution and used geometry. The temperature was maintained at $24{ }^{\circ} \mathrm{C}$ by a refrigerated/heating circulator (Julabo Labortechnik F32-HE) connected to the rheometer.

\section{Direct birefringence visualization}

Flow birefringence is caused by the orientation of optically anisotropic molecules (intrinsic birefringence) or deformation of an isotropic object (form birefringence) under applied flow. Wormlike micellar systems mainly exhibit intrinsic birefringence since the optical properties along and perpendicular to the micellar axis are different. At rest, i.e., at statistical orientation of the micelles $\left(45^{\circ}\right.$ angle), no anisotropy of the overall birefringence can be observed. Once shear forces are applied, orientation of the wormlike micelles sets in and the orientation angle drops towards $0^{\circ}$ and a difference in birefringence $\Delta n^{\prime}$ parallel and perpendicular to the flow direction can be observed. Visualization of the flow birefringence is obtained by an optical train using white light source, polarizer $\left(0^{\circ}\right.$ angle), sample, second polarizer $\left(90^{\circ}\right.$ angle), and camera. Anisotropic areas of the flow field (with high $\Delta n^{\prime}$ ) will appear brighter while isotropic-oriented material remains dark as the quiescent material. For this experiment, a transparent Couette cell with a 1-mm gap, a rotating inner cylinder of $30 \mathrm{~mm}$, and a height of $60 \mathrm{~mm}$ was used.

\section{SANS}

The experiments were performed with the SANS-I instrument of PSI, Villigen, Switzerland. The flow was generated in a planar contraction geometry with a contraction ratio of 8. The entire setup was composed of the flow cell, tubes, connectors, peristaltic pump, and cooling system allowing flow rates of $0.05-5 \mathrm{~cm}^{3} / \mathrm{s}$. The temperature was maintained at $24{ }^{\circ} \mathrm{C}$ by cooling fluid circulation along the aluminum frame. The water in the equimolar $\mathrm{CTAB} / \mathrm{NaSal}$ solutions was replaced by $\mathrm{D}_{2} \mathrm{O}$ to achieve better contrast in the smallangle neutron scattering patterns. The neutron wavelength was fixed at $8 \AA$. Data were collected on a two-dimensional He detector at distances of 2,6 , and $18 \mathrm{~m}$ covering a momentum transfer $q$ of $0.03-0.33 \mathrm{~nm}^{-1}$. The aperture diameter was $4 \mathrm{~mm}$. 


\section{Results and discussion \\ Diluted equimolar solutions (1.0-7.5 mM)}

\section{Flow curve hysteresis}

Figure 1 displays the flow curves (viscosity $\eta$ as a function of shear rate $\dot{\gamma}$ ) of dilute equimolar CTAB/NaSal solutions in the concentration regime of 1.0 to $7.5 \mathrm{mM}$. The squares represent upward shear stress sweep tests (from 0.1 to $10 \mathrm{~Pa}$ as shown in the inset of Fig. 1a), while the circles represent downward stress sweep tests (from 10 to $0.1 \mathrm{~Pa}$ ). Five flow curve measurements were carried out for each concentration in each sweep mode in order to obtain a "master curve" and the standard deviation for each solution.

Shear thickening was observed for all concentrations during an upward stress sweep. If the shear rate is further increased, the thickening regime will give way to shear thinning. It is rationalized that micelles can become longer due to the flow alignment and lead to a drop in viscosity while the entanglements and agglomerates of micelles are destroyed together with the shear-induced structures (Hofmann et al. 1991; Britton and Callaghan 1997; Vasudevan et al. 2008). Figure 2 shows the critical stress $\tau_{\mathrm{c}}^{\text {thickening }}$ when the shear thickening started on upward stress sweep experiments in Fig. 1. A linear increase with concentration could be verified. The thickening could arise by the transition of micelles from a random arrangement to long chains aligned in flow direction. Intuitively, the alignment of the chains should decrease the viscosity, but if shear-induced structures are formed, shear thickening can be rationalized by the organization of micellar bundles (Liu and Pine 1996; Herle et al. 2005; Hartmann and Cressely 1997a) or by aligned micelles in a metastable pseudo-nematic phase. This alignment generates electrostatic repulsion and van der Waals attraction between the micelles, leading to a potential/distance correlation depending on the ionic strength of the solution. The dependence of shear-induced structures on the shear rate comes with the possibility of overcoming a potential well, which allows the micelles to interact, collide, and change their kinetic energy (Hofmann et al. 1991). Thus, the micelles are transferred from the isotropic state into a metastable state of organization. Cates and Candau (2001) propose that shear thickening is due to the high end-cap energy of the micelles, which can form rings when the solution is motionless. The equilibrium is disturbed when shear rates higher than the inverse of the slowest relaxation time are applied, strongly increasing the stress. Considering mass balance, Frank et al. (2003) proposed that a local increase in concentration will generate also a local increase in viscosity, generating a shear rate variation in order to maintain the applied shear stress and
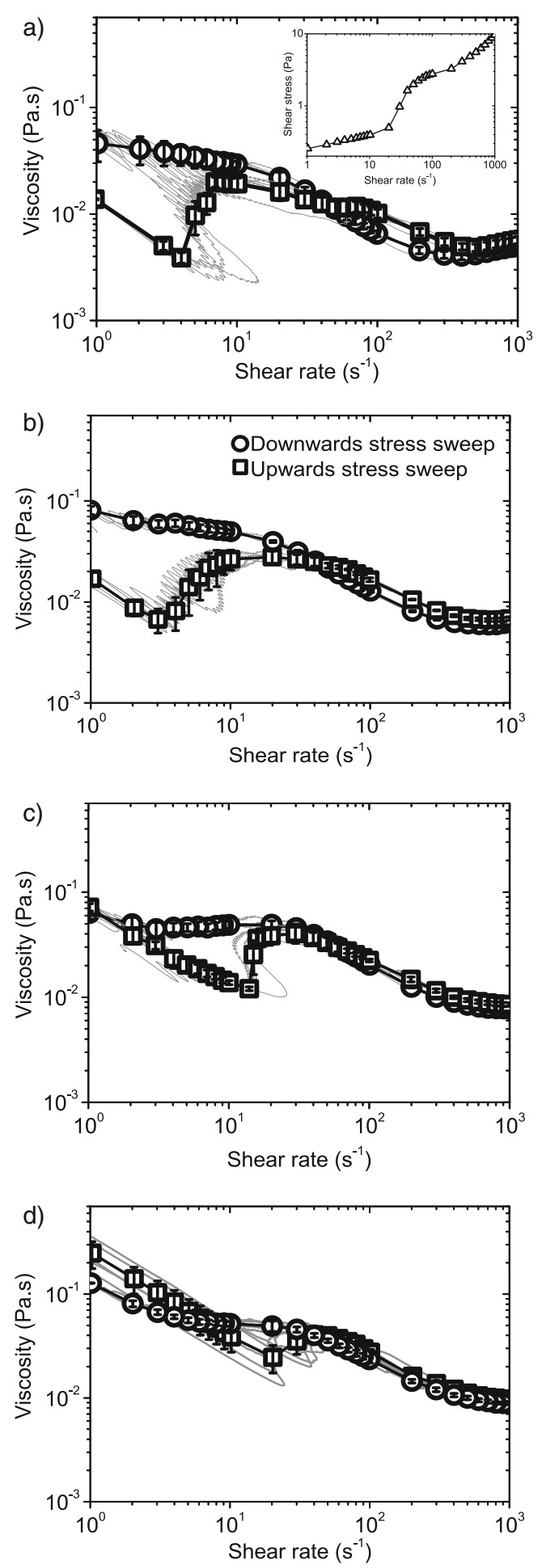

Fig. 1 Viscosity $\eta$ as a function of shear rate $\dot{\gamma}$ for dilute concentrations of equimolar CTAB/NaSal solutions with concentrations of a $1 \mathrm{mM}$, b $2.5 \mathrm{mM}$, c $5 \mathrm{mM}$, and $\mathbf{d} 7.5 \mathrm{mM}$. The inset on a shows the shear stress profile $\tau$ employed (squares: upward stress sweep, circles: downward stress sweep, data were obtained using the Couette geometry with a $1.25 \mathrm{~mm}$ gap, $T=24^{\circ} \mathrm{C}$ ) 


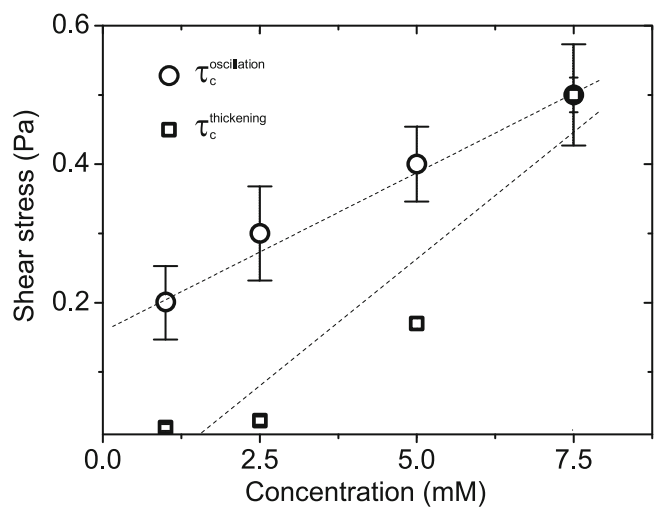

Fig. 2 The critical shear stresses $\tau_{\mathrm{c}}^{\text {thickening }}$ for shear thickening and shear-induced structure formation are observed in upward stress sweep experiments as a function of concentration (squares). The critical shear stresses $\tau_{\mathrm{c}}^{\text {oscillation }}$ for shear oscillation appear in downward stress sweep (circles)

avoiding possible mechanical instabilities. The migration of molecules from the region of high shear to the low shear can happen due to a shear rate-dependent chemical potential or by a hydrodynamically induced drift.

On the other hand, pure shear-thinning behavior was verified for downward sweep (circular symbols in Fig. 1). Since the test starts at high shear stresses, a pronounced micellar alignment is present in the gap and is maintained throughout the stress sweep to low shear rates. If the solution had already gone through upward (step 1, squares in Fig. 1) and downward (step 2, circles in Fig. 1) sweeps, when a third measurement was performed (upward stress sweep), the viscosity was the same as for step 2, i.e., without the shear-thickening region. However, the solution recovered its initial characteristics after a resting time, proving that shearinduced phases depend on time and stress applied to form and to break down. The different buildup scenarios of the shear-induced structure formation during the hysteresis loop can be explained by the time necessary before the structure recover its initial state by stress relaxation process and disentanglement of the micelles with a shorter timescale than the breakage (Cates 1987). Our results are in line with those by Hu et al. (1993b, 1994) who reported that if equimolar 1 $\mathrm{mM}$ CTAB/NaSal solutions are sheared in a flow of $100 \mathrm{~s}^{-1}$ at $24.4{ }^{\circ} \mathrm{C}$, the micelles and the relaxation times are short and independent of the shearing time. For increasing shear rates, large micellar structures appear and relax only very slowly.

The hysteresis area is reduced with the increase in concentration and vanishes for concentrations higher than $7.5 \mathrm{mM} \mathrm{CTAB} / \mathrm{NaSal}$ (Fig. 1d). According to the kinetics of breaking and recombination, a micellar break can occur anywhere along its length and the reverse reaction (entanglement) is proportional to the concentration of subchains and to the micellar size (Cates 1987). So faster processes at higher concentrations could be explained by this theory based on higher probability for the micelles to link and to break down. It could also be related to the increase in critical shear stresses $\tau_{\mathrm{c}}^{\text {thickening }}$ to start shear thickening (Fig. 2). The temperature is another factor that influences the hysteresis (Wunderlich and Brunn 1989). High temperature accelerates the breakdown process that is kinetically dependent. The maximum viscosity achieved by the solution increased as a function of the concentration, which could be explained by Vasudevan et al. (2008) who proposed that higher concentration solutions have more effective screening of electrostatic interactions that leads to longer micelle length. Longer micelles can entangle more easily, so smaller strains are required for the phase transition. Also, the relaxation process would be slower for highly entangled solutions.

\section{Viscosity oscillations under constant stress}

Controlled shear stress is achieved by the application of a constant torque to, e.g., the inner cylinder while the shear rate is measured. When the viscosity of the sample changes, the overall shear rate also changes in order to maintain the applied stress constant. In case of velocity shear banding, i.e., locally nonhomogeneous sample, it is proposed that distinct bands with different local shear rates can develop in order to maintain the average rate across the flow profile (Cates et al. 1993). The idea is that the shear rate increases to a critical level, so that the fluid has to relax to maintain the stress plateau by forming bands. In this way, the overall shear rate measured results from a small part of the solution with proportions described by a lever rule (Mair and Callaghan 1996). If the total mass of the sample is conserved, its redistribution in the shear bands is driven by concentration gradients depending on the applied shear rate/stress (Olmsted and Lu 1997). For vorticity banding, the shear stress cannot be accomplished in the fluid volume, and therefore temporal oscillations in shear stress were reported by, e.g., Wheeler et al. (1998), Fischer (2000), Herle et al. (2005, 2007), Azzouzi et al. (2005), and Vasudevan et al. (2008). In a Couette flow cell, such oscillations are attributed to generate heterogeneous shear-induced structures across the gap (Koch et al. 1998), to slip of the fluid at the rotating wall (Hu et al. 1998b), to cyclic formation and destruction of shear-induced structures (Herle et al. 2005), or to a stick-slip mechanism at the solid boundaries of the rheometer (Marin-Santibanez et al. 2006).

Oscillations in viscosity (and in shear rate) indicating the formation of shear bands are shown for all dilute $\mathrm{CTAB} / \mathrm{NaSal}$ sample in Fig. 1. The flow curves used to calculate the master curve as well as the error bars oscillate in viscosity at shear rates lower than $10 \mathrm{~s}^{-1}$. The onset shear stresses for the oscillations $\tau_{\mathrm{c}}^{\text {oscillation }}$ as well as standard 
deviations are shown in Fig. 2 where an increasing trend of $\tau_{\mathrm{c}}^{\text {oscillation }}$ as a function of concentration can be seen, a trend similar as seen by Herle et al. (2005). The maximum value of shear stresses, which could generate oscillatory signals before steady-state viscosity reading occurred, was around $0.5 \mathrm{~Pa}$ for a $7.5 \mathrm{mM}$ CTAB/NaSal solution. Similar oscillations were reported but not discussed by Hartmann and Cressely (1997b) for a 100/22-mM CTAB/NaSal solution. $\mathrm{Hu}$ et al. (1998b) suggested that those temporal fluctuations in the steady-state apparent viscosity are typical data obtained for dilute tris(2-hydroxyethyl) tallowalkyl ammonium acetate (TTAA) and NaSal solutions after an inducing time. Liu and Pine (1996) reported a chaotic nature of shearinduced structures that could explain such oscillations. We believe that such behavior is of general character, since the temporal oscillations indicate that the equilibrium state could not be achieved by the solution, so the microscopic balance of the micelles is not maintained and the macroscopic properties of the solution do not achieve stationary values (Hu et al. 1993b; Fischer 2000).

Coupling between the viscoelasticity of the solution and the moment of inertia of the rheometer (creep ringing) could be one of the explanations for this phenomenon, which makes it necessary to study the solution using different geometries. This effect was reported for gel-like solutions with relative high concentration and pronounced elasticity (Normand and Ravey 1997; Ewoldt and McKinley 2007). Vasudevan et al. (2008) suggested that dilute surfactant solutions are not qualitatively affected by inertial effects. Fluctuations could also be generated by elastic instabilities, since the phases, which contain shear-induced structures, are very elastic ( $\mathrm{Hu}$ and Matthys 1995). To address this concern, downward sweep tests were carried out in order to investigate the low shear rate oscillations. The temporal viscosity oscillations for the dilute regime (1- to $7.5-\mathrm{mM}$ CTAB/NaSal solutions) are shown in Fig. 3a where the initial viscosity increases up to factor of 350 times from 2.5to $5 \mathrm{mM}$ CTAB/NaSal solutions. As showed, all solutions with concentration lower than $10 \mathrm{mM}$ oscillated in shear at low stresses, but the oscillations from a $1 \mathrm{mM}$ solution were the most regular and their periodicity was further investigated. Figure $3 \mathrm{a}-\mathrm{c}$ shows the detail of the investigation of a $1 \mathrm{mM}$ CTAB/NaSal solution. Figure $3 \mathrm{~b}$ shows the viscosity as a function of time resulting from a downward stress sweep (1-0 Pa). The graphic is divided into three regions according to the viscosity behavior. In region I, the solution behaves nearly Newtonian with a viscosity around $5 \mathrm{mPa}$ (Fig. 3b, viscosity as a function of time) and shear thinning slope nearly to unity (Fig. 3c, viscosity as a function of shear rate). The critical shear stress $\left(\tau_{\mathrm{c}}^{\text {thickening }} \approx 0.4 \mathrm{~Pa}\right)$ provokes a sharp increase in viscosity, leading to a second plateau at $0.02 \mathrm{Pas}$ (region II in Fig. 3b, c). Decreasing the shear stress even more will lead to a second critical stress value $\tau_{\mathrm{c}}^{\text {oscillation }}$ of $\approx 0.18 \mathrm{~Pa}$, when shear-banding starts to divide the flow into two different viscosity regions (region III in Fig. 3b, c). The bifurcated viscosity data in Region III of Fig. $3 b$ and $c$ indicate the two stage situation the fluid is in (oscillation between two viscosity values and two shear rate values). It can be seen that the difference between the viscosities of the two bands increases until the rheometer achieves its maximum sensitivity and no further data can be collected. Back to Fig. 3a, which compares different concentrations, there is a clear induction period until a sharp increase in viscosity (Rehage and Hoffmann 1982; Hu and Matthys 1995), followed by a viscosity plateau and then by oscillating signals, which periodically changed the overall apparent viscosity of the solution. The induction periods for the sharp increase in viscosity get shorter with an increase in concentration. From concentrations of $7.5 \mathrm{mM}$, the viscosity increases since the start of the stress application. The approximate values are shown in the down-left corner of Fig. 3a. The appearance of the unstable flow in ramp down experiments indicates that oscillations are generated by the sample rather than by inertial effects.

Periodic oscillations were generated by shear stresses whose values increased with concentration from $0.05 \mathrm{~Pa}$ (1 $\mathrm{mM}$ solution) up to $0.2 \mathrm{~Pa}(7.5 \mathrm{mM})$. The stretched intervals are shown in Fig. 4b, c. The calculated Fouriertransform (FT) terms of the intervals are shown in Table 1 (Wilhelm et al. 1998, 1999; Kallus et al. 2001). Britton and Callaghan (1999) reported that the frequency of the oscillations between the shear-induced structures and the fluid phase interface depends on the concentration. All samples showed increasing oscillation frequency with concentration for both terms of the FT, while the amplitude decreased. However, the oscillations of the $7.5 \mathrm{mM}$ solution generated wider amplitudes when periodic. This could come from the limit superior and inferior of the oscillatory function which are not straight lines (see Fig. 4a); also, a second FT term could not be calculated for this concentration. The increase in frequency with concentration could indicate that at higher stresses and higher concentrations, the formation and destruction of shear-induced structures occur more rapidly, which agrees with the decrease in amplitude, since the structure of the phases also becomes more similar. However, comparing the oscillation of the same solution while the shear stress steps decrease, the amplitude increases (as in Fig. 3a) until lower limit when the instrument is not sensitive enough to collect data any further.

Figure $4 \mathrm{a}$ shows an example of the oscillations at low shear stresses (1 to $0.001 \mathrm{~Pa}$ ) applied for $350 \mathrm{~s}$ on dilute concentrations of $\mathrm{CTAB} / \mathrm{NaSal}$. The results confirmed that oscillations in shear rate at low stresses depend on concentration and happened to all solutions in the dilute regime. If a constant stress is applied within the range of oscillating signal, after a short induction time, the oscillations start 
Fig. 3 Evaluation of possible creep ringing and elastic instabilities in ramp down shear stress experiments. a Viscosity $\eta$ as a function of time $t$ for dilute equimolar $\mathrm{CTAB} / \mathrm{NaSal}$ solutions. The inset graph shows the downward stress profile $\tau$ used for the measurement. b Shear-banding oscillations of the 1-mM CTAB/NaSal solution as a function of the time $t$ represented by the oscillation of the viscosity while decreasing the applied shear stress (inset graphic). c Flow curve for the same measurement (all data were obtained using the Couette geometry with a $1.25 \mathrm{~mm}$ gap, $T=24{ }^{\circ} \mathrm{C}$ )
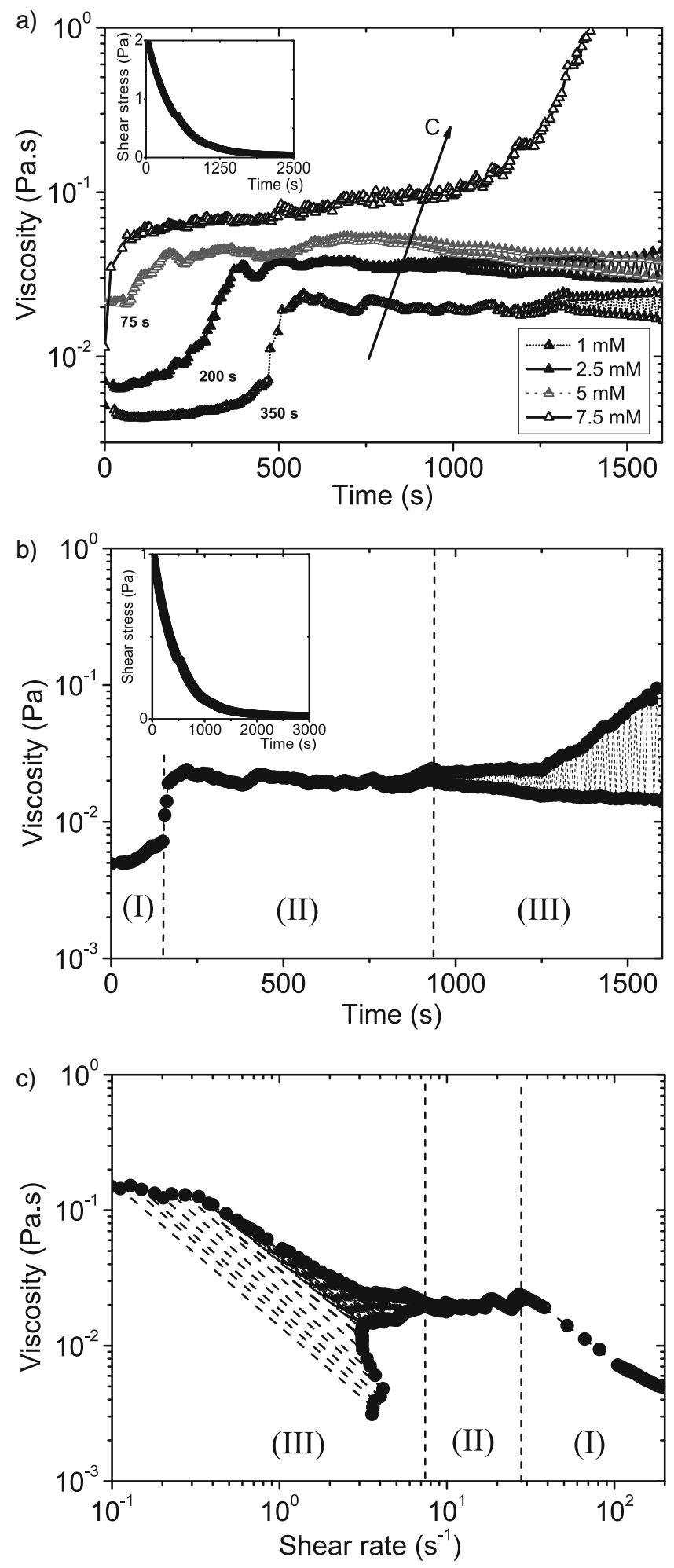

extinguished. For the $7.5 \mathrm{mM}$ CTAB/NaSal solutions, oscillations were observed in a short range of shear stresses (from 0.4 to $0.2 \mathrm{~Pa}$ ), while for the $1 \mathrm{mM} \mathrm{CTAB} / \mathrm{NaSal}$ solution, the range was much larger (from 0.1 to $0.01 \mathrm{~Pa}$ ). The $1 \mathrm{mM} \mathrm{CTAB} / \mathrm{NaSal}$ solution has longer relaxation and become permanent, existing for several hours of shearing (effect also seen by Azzouzi et al. (2005) in temporal oscillations of shear stress).

Table 1 summarizes the stress values when the shear oscillations started, became periodic, and, finally, were 


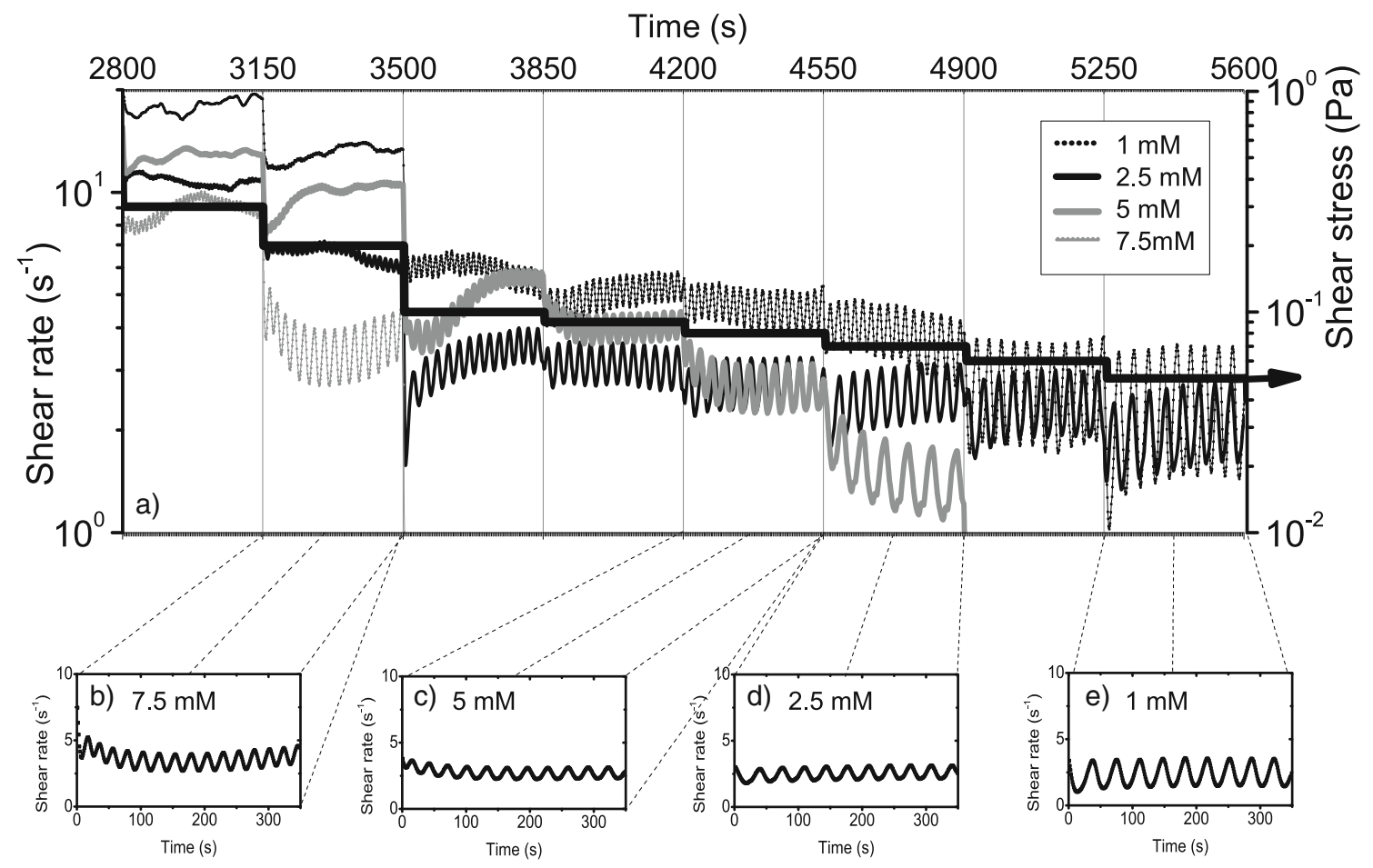

Fig. 4 a Constant shear stress step experiment in the intervals of $350 \mathrm{~s}$ showing oscillations in shear rate for dilute equimolar CTAB/NaSal solutions. The lower graphics are amplifications of the interval when the oscillations were nearly periodic: $\mathbf{b} 7.5 \mathrm{mM}$ at $0.2 \mathrm{~Pa}$, c $5 \mathrm{mM}$ at $0.08 \mathrm{~Pa}, \mathbf{d} 2.5 \mathrm{mM}$ at $0.07 \mathrm{~Pa}$, and e $1 \mathrm{mM}$ at $0.05 \mathrm{~Pa}$ (data were obtained using the Couette geometry with a $1.25 \mathrm{~mm}$ gap, $T=24{ }^{\circ} \mathrm{C}$ ) time compared to higher concentrations, which depends on destruction/relaxation of shear-induced structures to recover its initial state. Thus, shear-induced structures are formed easily in high-concentration solutions, as does the viscosity oscillation between relaxed states and shear-induced structures during relaxation process.

To determine the frequency of those oscillations, steady shear stresses (lower than $\tau_{\mathrm{c}}^{\text {oscillation }}=\tau_{\mathrm{c}_{2}}=0.18 \mathrm{~Pa}$ ) were applied for $900 \mathrm{~s}$ with a resolution of $F_{\mathrm{s}}=0.39 \mathrm{~s}^{-1}$. Figure 5 shows the oscillations of the shear rate as a function of time. The amplitude and period of the oscillations are dependent on the shear stress applied. However, the shear bands resulting from $\tau=0.03,0.04$, and $0.05 \mathrm{~Pa}$ seem to have an upper limit to their amplitudes, achieving a maximum shear rate $\dot{\gamma}_{\max }$ of about $3.7-4.1 \mathrm{~s}^{-1}$, which increases slightly after the transition to $\tau=0.06 \mathrm{~Pa}$. The lower limit (minimum shear rate, $\dot{\gamma}_{\text {min }}$ ) does not show the same constant amplitude for all stresses. This is similar to results presented by Fischer (2000). With $\tau=0.03$ and $0.04 \mathrm{~Pa}$, a continuous decrease of $\dot{\gamma}_{\min }$ with time was observed, meaning that the difference between the shear bands formed also increases with time. Probably, it is a result of the slow transient alignment of the micelles at low shear stresses, leading to the thickening of the solution. It could explain the well-defined amplitude $\left(\dot{\gamma}_{\max }\right.$ and $\left.\dot{\gamma}_{\min }\right)$ on the interval of $\tau=0.05$ since a minimum shear stress $\dot{\gamma}_{\min }$ may be necessary to align efficiently the wormlike micelles along the gap in this period of time. In the interval $\tau=0.06 \mathrm{~Pa}$, an abrupt decrease of amplitude and period was visualized, which were no longer well defined. The periodic oscillation of the $1 \mathrm{mM}$
Table 1 Critical shear stress values and Fourier-transform terms of the periodic oscillations as a function of concentration

\begin{tabular}{|c|c|c|c|c|c|c|c|}
\hline \multirow{2}{*}{$\begin{array}{l}\text { Concentration } \\
(\mathrm{mM})\end{array}$} & \multicolumn{3}{|c|}{ Critical shear stress oscillations $(\mathrm{Pa})$} & \multicolumn{2}{|l|}{1 st term } & \multicolumn{2}{|l|}{ 2nd term } \\
\hline & Start & Periodic & End & $\begin{array}{l}\text { Amplitude } \\
\left(\mathrm{s}^{-1}\right)\end{array}$ & $\begin{array}{l}\text { Frequency } \\
(\mathrm{Hz})\end{array}$ & $\begin{array}{l}\text { Amplitude } \\
\left(\mathrm{s}^{-1}\right)\end{array}$ & $\begin{array}{l}\text { Frequency } \\
(\mathrm{Hz})\end{array}$ \\
\hline 1.0 & 0.10 & 0.05 & 0.02 & 0.926 & 0.021 & 0.082 & 0.047 \\
\hline 2.5 & 0.30 & 0.07 & 0.01 & 0.361 & 0.029 & 0.045 & 0.058 \\
\hline 5.0 & 0.20 & 0.08 & 0.06 & 0.376 & 0.032 & 0.032 & 0.063 \\
\hline 7.5 & 0.40 & 0.20 & 0.10 & 0.476 & 0.040 & 0.000 & 0.000 \\
\hline
\end{tabular}




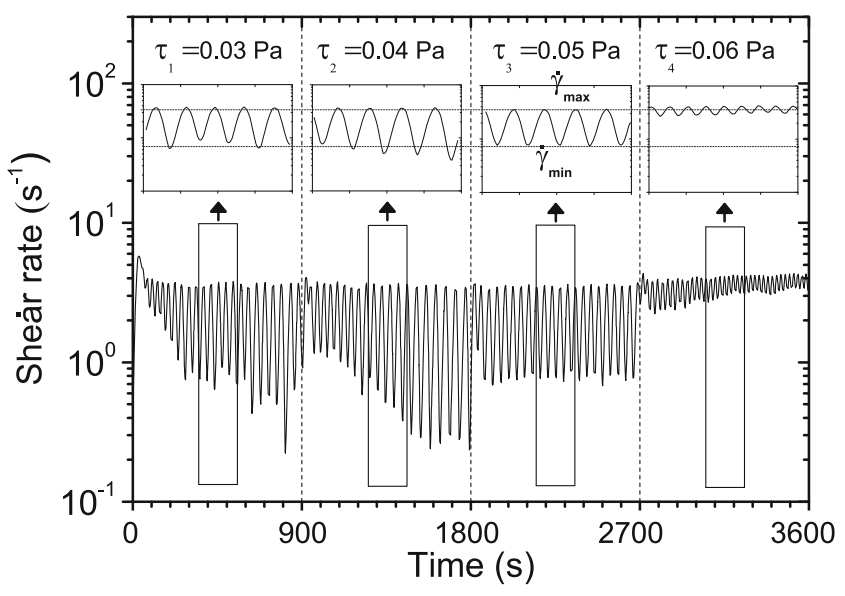

Fig. 5 Temporal oscillations of the shear rate $\dot{\gamma}$ of the 1-mM $\mathrm{CTAB} / \mathrm{NaSal}$ solution at the indicated shear stresses applied in steps every $900 \mathrm{~s}$. For clarity, the inset graphics show an interval of 200-s of each shear stress used (data were obtained using the Couette geometry with a $1.25 \mathrm{~mm}$ gap, $T=24^{\circ} \mathrm{C}$ )

CTAB/NaSal solution at $\tau=0.05 \mathrm{~Pa}$ can be interpreted as well-defined bands which are formed and destroyed with a characteristic frequency.

\section{Direct birefringence visualization}

When micellar aggregates form shear-induced structures, the structure becomes strongly aligned with the shear flow and show flow birefringence and spatial anisotropy. $\mathrm{Hu}$ et al. (1998a) suggested, based on flow birefringence results, that the shear-thickening transition in low-concentration TTAA/NaSal solution consists of four regimes with different rheological behavior and kinetics of formation once the shear stress is increased steadily. To verify the formation of shear bands, direct birefringence visualization was utilized. The effect of shear flow on low-concentration CTAB/NaSal solutions was investigated in a transparent Couette cell with a 1-mm gap width. In the following, the results for the equimolar $7.5 \mathrm{mM} \mathrm{CTAB/NaSal}$ solution are shown, since lower concentrations only generated very weak birefringence signals, which are hard to capture.

When motionless, the solution results in dark image throughout the flow cell (as can be seen in region I of Fig. $6)$. The bright edges come from the upper and lower parts of the inner cylinder that is made by white polymeric material while the bright spots originate from bubbles in the solution. Birefringence first appears at approximately $20 \mathrm{~s}^{-1}$ when the solution exhibits slow micellar alignment. After the transition (in region II), shear-induced structures nucleate inhomogeneously at the inner cylinder, which coexist with the shear-thickening behavior of the solution. Region III starts after $200 \mathrm{~s}^{-1}$, differing from region II based on the extension of the shear bands, since here the bands nucleate homogeneously throughout the shear cell. When the shear increases, a higher number of smaller bands are formed, since the formation and destruction processes happen more quickly (Hu and Matthys 1995).

The main difference from the results presented by $\mathrm{Hu}$ et al. (1998a) is the band formation mechanism. Here, the bands appear and disappear within the Couette cell diagonally, causing the rotating inner cylinder to move in an unsteady way under shear. Marin-Santibanez et al. (2006) reported the same effect and attributed $t$ to an apparent adhesive periodic failure at the liquid-solid interface.

\section{Gap effects}

To verify the wall effect on the viscosity oscillating and on shear thickening, the rheological response of the 1-mM $\mathrm{CTAB} / \mathrm{NaSal}$ solution was measured using Couette geometries with different inner cylinder diameters, leading to gap sizes of $0.5,1.25,2.5,3.75$, and $5 \mathrm{~mm}$. The results for upward stress sweep tests are depicted in Fig. 7. Oscillations and shear thickening are very pronounced for the 1.25and 2.5-mm gaps, while at higher gap widths, the oscillations are less stable. At a $0.5-\mathrm{mm}$ gap, shear thickening did not appear. The downward stress sweep experiments are not shown in Fig. 7, but they were also carried out. The hysteresis area reduced with the gap increase, confirming that the volume of the solution and the confinement influence the shear-induced structures' formation.

The viscosity is plotted in Fig. 8 as a function of time for downward stress sweep (20 to $0 \mathrm{~Pa}$ ) with different gap sizes. The induction time for the temporal shear oscillations increased with the gap size. Additionally, for gaps larger than $1.25 \mathrm{~mm}$, the stable zone in viscosity before the critical shear stress $\tau_{\mathrm{c}}^{\text {thickening }}$ appears also increases with

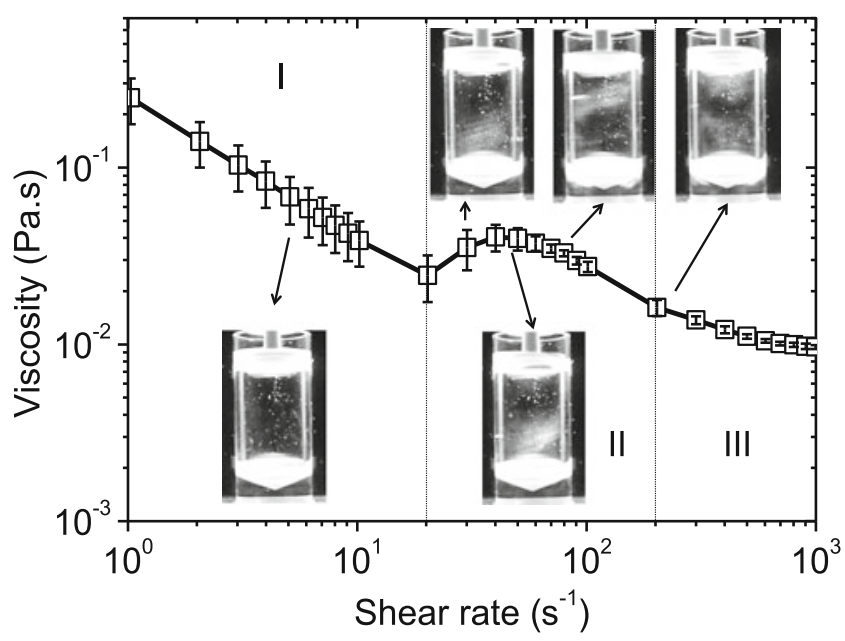

Fig. 6 Birefringence pictures of the $7.5 \mathrm{mM}$ CTAB/NaSal solution during an upward stress sweep test 


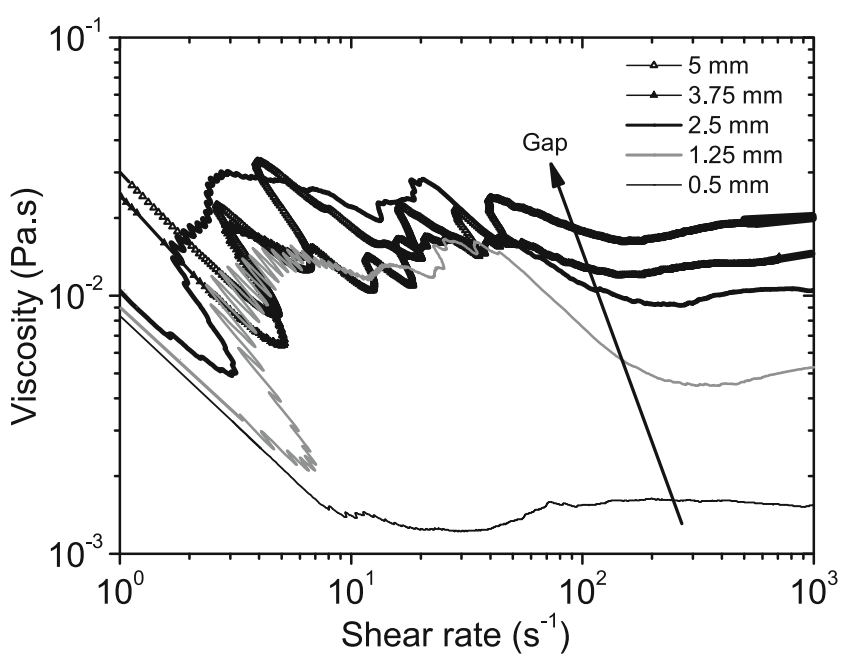

Fig. 7 Effect of the gap width on the shear oscillations and thickening in a upward stress sweep experiment (data were obtained using a Couette geometry with different gap sizes of $0.5,1.25,2.5,3.75$, and $5 \mathrm{~mm}, T=24{ }^{\circ} \mathrm{C}$ )

gap size. The onset of $\tau_{\mathrm{c}}^{\text {thickening }}$ is moved to lower shear rates with increasing gap size. It is known that shear rate in Couette flow cells is proportional to the gap width, so in a wide-gap cell, the overall shear rate measured can be divided into regions where shear banding occurs (Dhont and Briels 2008), possibly leading to those fluctuations and differences due to gap width. The temporal oscillations were confirmed to originate from the interaction of the solution with the rotational cylinder wall, which makes the micelles align, increasing the order and forming different phases with specific properties within the same liquid (shear-induced structures).

Figure 9 shows the induction time and the critical shear stress $\tau_{\mathfrak{c}}^{\text {oscillation }}$ as a function of sample volume in Couette cells with different gaps. For both variables, a clear linear

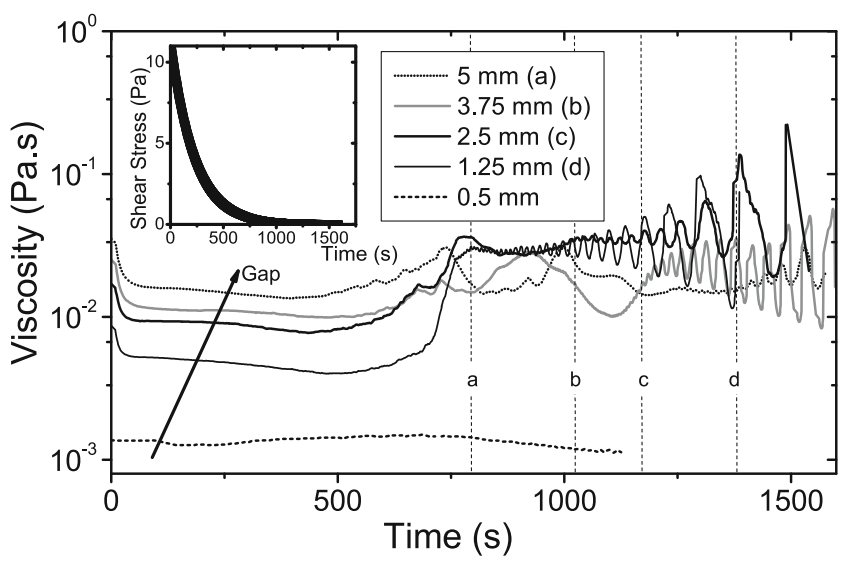

Fig. 8 Effect of the Couette gap width on the viscosity of the $1 \mathrm{mM}$ $\mathrm{CTAB} / \mathrm{NaSal}$ solution (data obtained using a Couette geometry with different gap sizes of $0.5,1.25,2.5,3.75$, and $5 \mathrm{~mm}, T=24^{\circ} \mathrm{C}$ )

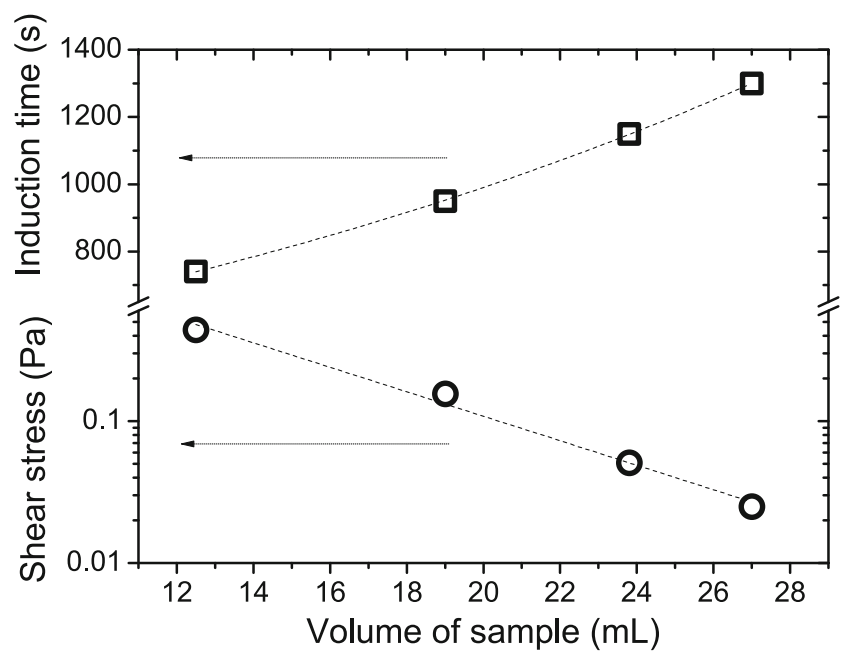

Fig. 9 Induction time and shear stress at the onset of temporal shear oscillations as a function of volume of sample (proportional to the gap width of the Couette flow cell with different gap sizes of 0.5, 1.25, 2.5, 3.75 , and $5 \mathrm{~mm}, T=24{ }^{\circ} \mathrm{C}$ )

relation was obtained, showing that larger volumes of sample need longer induction times before oscillation begins. As discussed by Wunderlich and Brunn (1989), it influences the time necessary for the micelles to achieve an equilibrium, once surfactant molecules are continuously joining and leaving the micelle structure. The authors published similar results for an equimolar $1.38 \mathrm{mM} \mathrm{CTAB} / \mathrm{NaSal}$ solution, in which the maximum viscosity measured (after shear thickening) increased with the gap width until an upper limit, when the maximum viscosity could not increase anymore. Furthermore, longer residence times in the Couette cell could allow shear-induced structures to grow, resulting in more rigid structures as seen in capillary flow experiments (Marin-Santibanez et al. 2006). A minimum gap width was also reported by Herle et al. (2005).

\section{Effect of the geometry}

Herle et al. (2005) performed similar experiments using parallel-plate geometry for equimolar $40 \mathrm{mM}$ cetylperidinium chloride and $\mathrm{NaSal}$ with gaps smaller than $1 \mathrm{~mm}$. They showed that if the gap is under $0.25 \mathrm{~mm}$, no transition to shear thickening occurs and the solution is purely shear thinning. It suggests that there is a critical dimension necessary for the shear-induced structures' formation. Figure 10 shows the same experiment for the $1 \mathrm{mM} \mathrm{CTAB} / \mathrm{NaSal}$ solution using parallel-plate geometry but for gaps under $1.5 \mathrm{~mm}$. For gaps under $0.5 \mathrm{~mm}$, no shear thickening of the solution was verified. The maximum viscosity after the shear-thickening transition decreases with the concentration, although for gaps between 1 and $1.5 \mathrm{~mm}$, they achieved nearly the same level, considering an average of the fluctuations around $10 \mathrm{~s}^{-1}$. 


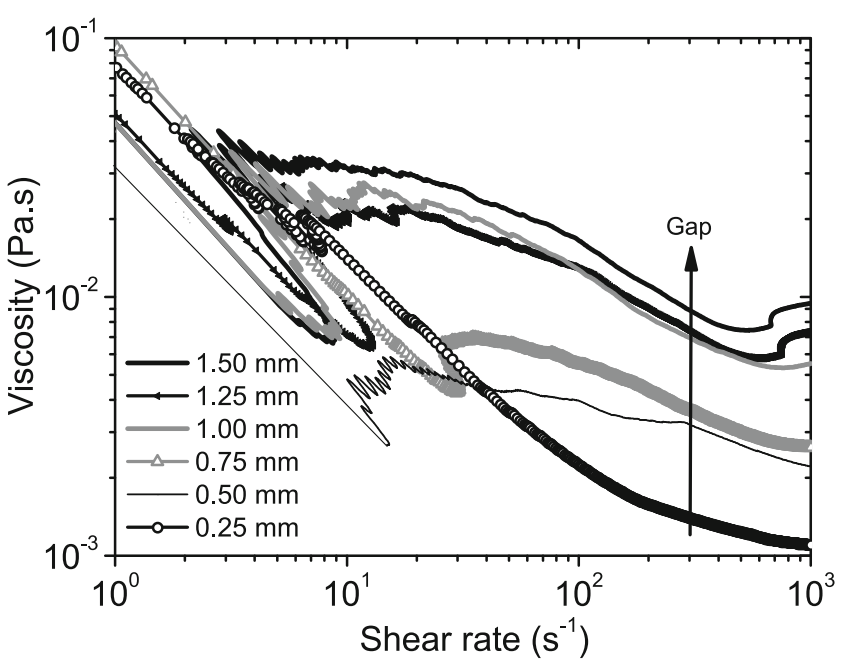

Fig. 10 Effect of the gap on upward stress sweep of the $1 \mathrm{mM}$ $\mathrm{CTAB} / \mathrm{NaSal}$ solution using parallel-plate geometry with different gap sizes of $0.25,0.5,0.75,1.0$, and $1.25 \mathrm{~mm}\left(T=24{ }^{\circ} \mathrm{C}\right)$

The effects of the geometry on the oscillations and on the shear thickening was also studied using the coneplate geometry. Upward (gray lines) and downward (black lines) stress sweep tests are shown for all geometries in Fig. 11. The shear-thickening transition was visualized for all geometries with gaps larger than $1.25 \mathrm{~mm}$ in upward stress sweep mode, starting first in the Couette cell and then in the cone-plate and plate-plate geometries, respectively. The cone-plate geometry creates constant shear rates, so if the shear thickening due to shear-induced structure formation also happened with this geometry, it results from structural change in the solution and not just because of shear

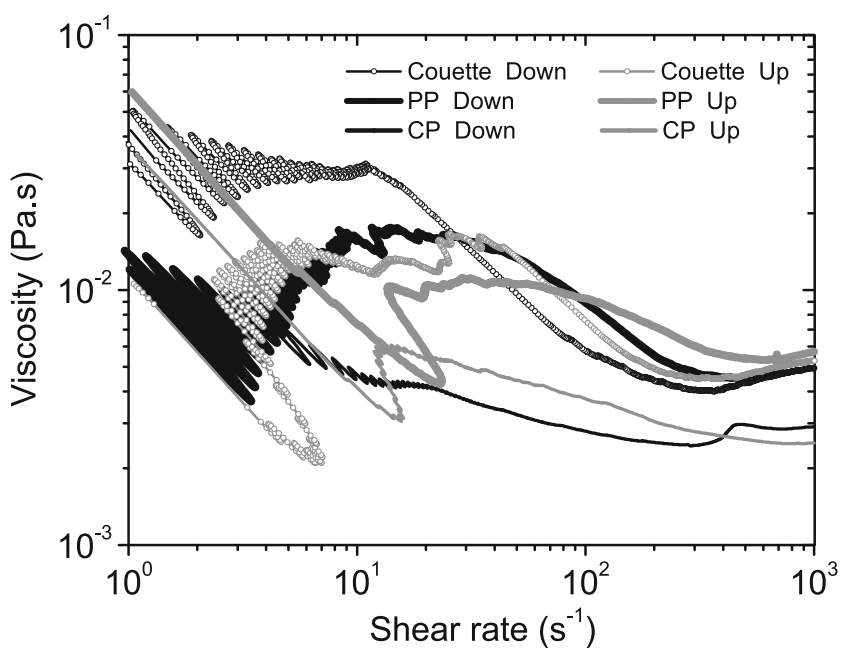

Fig. 11 Comparison between different geometries for downward (black lines) and upward (gray lines) stress sweep experiments for the $1 \mathrm{mM} \mathrm{CTAB} / \mathrm{NaSal}$ solution (data were obtained using the different geometries with a $1.25 \mathrm{~mm}$ gap, $T=24^{\circ} \mathrm{C}$ ) gradients within the flow cell (Herle et al. 2005). Downward experiments with different geometries also generated oscillations at shear rates lower than $20 \mathrm{~s}^{-1}$ with increased amplitude. The viscosity oscillations with the CP geometry were weaker when compared to the other geometries, proving that this effect in dilute equimolar $\mathrm{CTAB} / \mathrm{NaSal}$ solutions also originates from microstructural changes.

Semi-dilute solutions $(10-100 \mathrm{mM})$

\section{Flow curves}

Figure 12 shows the flow curves of equimolar CTAB/NaSal solutions with concentrations between 7.5 and $100 \mathrm{mM}$. The oscillations at low shear rates, which are present at lower concentration, were not observed at concentrations higher than $7.5 \mathrm{mM}$, due to the pronounced viscoelastic response of these solutions when compared to the lower concentration ones (Kim and Yang 2000). The main difference compared to low-concentration solutions is the zero-shear viscosity, which extends until approximately $1 \mathrm{~s}^{-1}$ (e.g., $100 \mathrm{mM}$ solution). High shear rates could promote intermicelle association and then network formation (Vasudevan et al. 2008); further shear thinning could be generated by the faster unravelling of the micelles and the end-to-end agglomeration can also be increased (Teixeira et al. 2005). To compare the elastic and viscous part of the solutions, dynamic stress tests were carried out. Figure $12 \mathrm{~b}$ shows the storage modulus $G^{\prime}$ and Fig. 12c shows the loss modulus $G^{\prime \prime}$. For the $7.5 \mathrm{mM}$ solution, only the loss modulus could be detected while $G^{\prime}$ appeared for all solutions with concentrations higher than a $10 \mathrm{mM}$ CTAB/NaSal solution. Here, the storage modulus exceeded the loss modulus $G^{\prime}>G^{\prime \prime}$, i.e., indicating a network formation in the semi-dilute regime.

\section{Direct birefringence visualization}

The shear-thinning behavior coupled with shear band formation was again visualized for all solutions by direct birefringence visualization in the shear rate regime of $0.001-$ $1,000 \mathrm{~s}^{-1}$ (see Fig. 13). The upward stress sweep test ( 0.1 to $100 \mathrm{~Pa}$ ) is divided into four regions according to the organization of the shear bands in the Couette cell. The first region shows the formation of the shear-induced structures with increasing shear stress. The differences between the image at $0.0022 \mathrm{~Pa}$ (region I, left) and the one at $0.06 \mathrm{~Pa}$ (region I, right) indicate that the micelles are aligned in the diagonal direction of the flow cell. When the shear stress reaches a plateau in region II (shear thinning the solution), large shearinduced structures are formed over the entire flow cell. The most interesting fact in this experiment is the abrupt transition between regions II and III: when the shear stress 
Fig. 12 a Flow curves of $\mathrm{CTAB} / \mathrm{NaSal}$ solutions with different concentrations; stress sweep tests: $\mathbf{b}$ storage modulus as a function of shear stress and $\mathbf{c}$ loss modulus as a function of shear stress, the variable $C$ stands for the increase in solution concentration (data were obtained using the Couette geometry with a $1.25 \mathrm{~mm}$ gap, $T=24{ }^{\circ} \mathrm{C}$ )
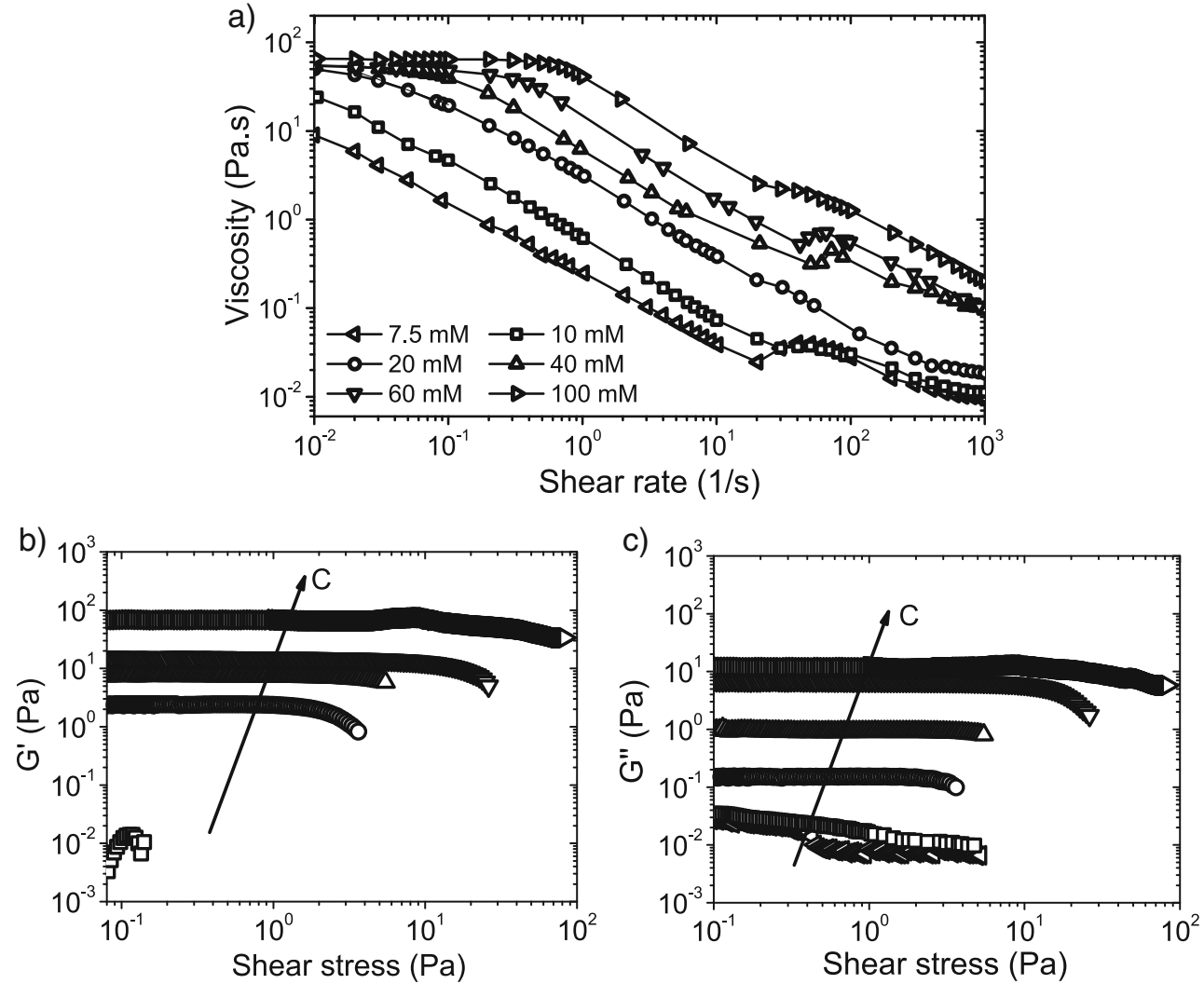

reaches a value of approximately $11 \mathrm{~Pa}$, the large homogeneous shear band breaks into many small bands. These cause the angular speed of the inner cylinder to increase for some seconds until it achieves equilibrium again. This phenomena corresponds to a failure of shear-induced structures by "cracking of the bulk fluid" accompanied by flow instability, which was described as a fraction process by $\mathrm{Hu}$ et al. (1994). From region III to region IV, the bands build up again including some oscillations and a weak shear-thickening region. This could be connected to unstable larger shear band formation seen in the birefringence signal.

\section{Degradation of the 1:1 CTAB/NaSal solution}

\section{Leaching of rubber tubing compounds into CTAB/NaSal solutions}

The mechanical and chemical degradation of the wormlike micelles may be due to the breakage of the micelles in length or to the shape transition from wormlike to spherical micelles or other morphologies (Hoffmann and Ulbricht 1989). This affects the rheological response and the possible application of the solution as, e.g., drag-reducing fluid. The equimolar $10 \mathrm{mM} \mathrm{CTAB} / \mathrm{NaSal}$ solution was used to evaluate the influence of mechanical load (accumulated deformation) or chemical poisoning of the micelles. To verify the effect of pure shear without contact with polymers, the solution was placed in a Couette geometry (gap $1.25 \mathrm{~mm}$ ) under $\tau=10 \mathrm{~Pa}$ for $10 \mathrm{~h}$. During this period, no effective variation in the viscosity was measured, indicating that the micelles do not suffer degradation when sheared. However, after contact with several brands of rubber tubing, the viscosity of the solution changed. The variation was determined by the measurement of the viscosity before and after contact with the tubing (Fig. 14). Around $2 \mathrm{~g}$ of

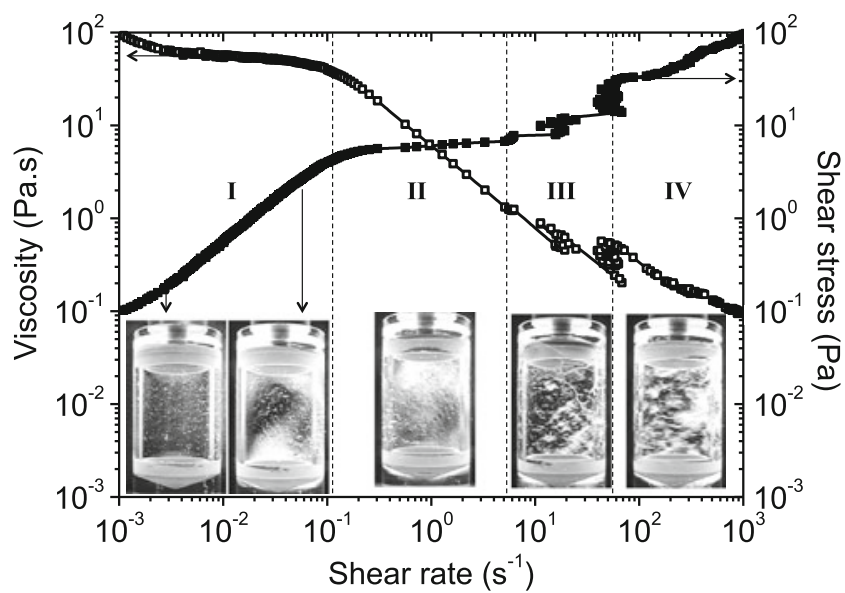

Fig. 13 Birefringence images of the equimolar $40 \mathrm{mM}$ CTAB/NaSal solution under upward stress sweep analysis (data were obtained using the Couette geometry with a $1 \mathrm{~mm}$ gap, $T=24^{\circ} \mathrm{C}$ ) 


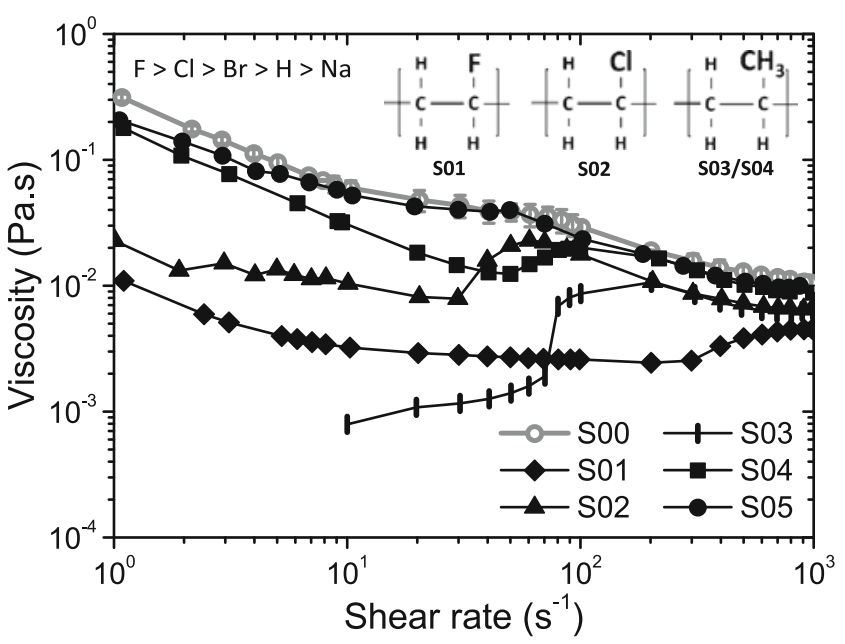

Fig. 14 Comparison between the flow curves of the equimolar 10-mM $\mathrm{CTAB} / \mathrm{NaSal}$ solution before and after contact with rubber peristaltic pump tubing. The gray curve is the pure $10 \mathrm{mM}$ solution (data were obtained using the Couette geometry with a $1.25 \mathrm{~mm}$ gap, $T=24{ }^{\circ} \mathrm{C}$ )

polymeric tubing (tubings for peristaltic pump by Ismatec, Wertheim, Germany) was immersed in $30 \mathrm{ml}$ of the $10 \mathrm{mM}$ $\mathrm{CTAB} / \mathrm{NaSal}$ solution for $48 \mathrm{~h}$, following the procedure described in ISO-1817 (ISO 2005). The composition of the tubings described in Table 2 is given by the supplier. The weight losses were calculated based on the difference of the tubing mass before and after immersion in solution, showing that some compounds (additives, plasticizer, or polymer) were extracted/leached into the surfactant solution. Following the same method, polymeric samples were also immersed in toluene to extract the plasticizer which could react with the surfactant solution, causing its degradation.

The systems S01 (fluorelastomer) and S02 (polyvinylchloride, PVC) had the highest weight losses after a 48-h contact with the CTAB/NaSal solutions. Saito and Mizuta (1967) proved that the solubilization of polyvinylacetate by an anionic surfactant solution is possible by formation of complexes of polyelectrolyte character. The same reaction could have happened in the present experiment, where the cationic surfactant could react with compounds from the tubing material. The driving force could be the electronegativity of the halogens groups (fluorine and chlorine), which are part of the composition (the electronegativity series is given by $\mathrm{F}>\mathrm{Cl}>\mathrm{Br}>\mathrm{H}>\mathrm{Na}$ as also shown in Fig. 14 at the right-up corner). The polarities of both groups are higher than the bromide in solution (CTAB counterion), possibly leading to a more stable chemical bond. Also, the cation $\mathrm{Na}^{+}$from the NaSal salt would react preferentially with these anions, which could influence the growth in length of the wormlike micelles. However, Gamboa and Sepulveda (1986) observed that the viscosity strongly depends on the nature of the counterions and that the stronger they are bonded, the more the viscosity increases. According to the effects of the anionic counterions on the viscosity of cationic solutions, the order is $\mathrm{Br}^{-}>\mathrm{Cl}^{-}>\mathrm{F}^{-}$(Hartmann and Cressely 1997b). Since the polymers and the surfactant solution have similar functional groups, the permeation rate of the solution into the polymer will increase followed by diffusion of the halogens due to concentration difference within the system. Comparing S01 and S02 to S00 (10 mM CTAB/NaSal without interacting with any polymer), one can see that the viscosity of $\mathrm{S} 01$ (with $\mathrm{F}^{-}$) was more affected than the $\mathrm{S} 02$ (with $\mathrm{Cl}^{-}$). It could be interpreted as if the breakdown of the wormlike micelles was less intense in the second case, since after contact with the rubber tubing, the solution behaved like lower concentration CTAB/NaSal solutions, showing even the shear-thickening region. This shows that probably the release of $\mathrm{Cl}^{-}$ions into the solution made some of the wormlike micelles to break down or undergo shape transition into spherical micelles due to new reactions between the ions in solution. Table 2 shows also that S01 is not soluble in toluene. The same procedure was performed in acetone but no leaching of the additives was seen, which could indicate the solubilization by chemical reaction with the surfactant solution. S02 exhibited high weight loss in toluene (almost $40 \%$ ). After this interaction, the tubing was completely stiff, confirming the leaching of plasticizer.
Table 2 Polymer compositions and weight losses after immersion in equimolar 10 mM CTAB/NaSal and toluene

\begin{tabular}{|c|c|c|c|c|}
\hline \multirow{2}{*}{$\begin{array}{l}\text { Sample } \\
\text { name }\end{array}$} & \multirow{2}{*}{$\begin{array}{l}\text { Commercial } \\
\text { name }\end{array}$} & \multirow[t]{2}{*}{ Composition of the polymer } & \multicolumn{2}{|l|}{ Weight loss (\%) } \\
\hline & & & In $\mathrm{CTAB} / \mathrm{NaSal}$ & In toluene \\
\hline S00 & - & - & - & - \\
\hline S01 & Fluran ${ }^{\circledR}$ HCA & Fuorelastomer & 1.27 & 0.00 \\
\hline S02 & Tygon ${ }^{\circledR}$ R-3607 & PVC + plasticizer & 0.94 & 39.71 \\
\hline S03 & PharMed ${ }^{\circledR}$ & $\mathrm{PP}+$ plasticizer + lubricants & 0.85 & 40.01 \\
\hline S04 & Tygon ${ }^{\circledR}$ MHLL & $\begin{array}{l}\text { Elastomeric PP without } \\
\text { plasticizer/lubricant }\end{array}$ & 0.12 & 34.98 \\
\hline S05 & Tygon ${ }^{\circledR}$ MHSL & $\begin{array}{l}\text { Polyolefin blend without } \\
\text { plasticizer/lubricant }\end{array}$ & 0.01 & 5.74 \\
\hline
\end{tabular}


The largest change in viscosity was observed for the $\mathrm{S} 03$ system composed of polypropylene (just nonpolar groups), plasticizer, and lubricant. These additives could allow the permeation of the micellar solution into the polymer and since the plasticizers have the tendency to migrate to the surface of the polymer (Schweitzer 2006), it could be leached by the solution, leading to the observed weight loss of the sample. Once these low weight plasticizer molecules are released into the solution, they could disaggregate the wormlike micelles. Considering the related flow curve, one can see that after this interaction with the polymer, the solution showed very low viscosity at low shear rates and a shear-thickening region. S04 exhibited lower interaction with the solution under the same conditions, resulting in lower weight loss and viscosity variation even at low shear rates (Tripathi 2002). However, comparing the solubility in toluene, large weight losses for $\mathrm{S} 03$ and S04 were observed. For S03, it is easy to assure that the additives could have leached from the polymer, but assuming that S04 was free of plasticizer and lubricant, further details must be studied to understand the interaction of this polymer with $\mathrm{CTAB} / \mathrm{NaSal}$ solution. One possible explanation is the solubilization of hydrocarbons investigated in surfactant solutions by Hoffmann and Ulbricht (1989). The authors proposed that long rods could be transformed into globular structures when very small quantities of hydrocarbons were solubilized, changing the rheology and the shear-induced structures formation of the surfactant. Finally, S05 was chosen for further experiments since the weight loss and flow curve comparisons did not show any disadvantages. Very little is known about its exact composition, but it is well known that polyethylene (PE) and polypropylene (PP) with fillers are the most common polymers used in polyolefin blends.

\section{SANS results}

Figure 15 shows the SANS patterns of equimolar $10 \mathrm{mM}$ $\mathrm{CTAB} / \mathrm{NaSal}$ under flow at different times. The solution was circulated through a contraction flow cell (Fig. 15a) with a volumetric flow rate of $0.09 \mathrm{~cm}^{3} / \mathrm{s}$ generated by a peristaltic pump. SANS scattering patterns were measured at the entrance region of the contraction and the effect of the flow in the alignment can clearly be seen.

When the tubing used consisted of S03 (described in Table 2), the $10 \mathrm{mM} \mathrm{CTAB} / \mathrm{NaSal}$ solution lost micellar organization in a short period of time. This can be seen in the SANS pattern after $500 \mathrm{~min}$ as a loss of anisotropic scattering (Fig. 15b). To obtain a wide range of momentum transfer values $q$, measurements with different detector distances from the sample $(2,6$, and $18 \mathrm{~m})$ are necessary, since each one is able to generate better results in a specific area of the $q$ range. After collecting the scattering patterns, the images were calibrated according to the transmission of water and the empty flow cell. The experimental curves of $I(q)$ as a function of the $q$ should be fitted with theoretical models to allow the determination of the micelle diameter and length. The equimolar $10 \mathrm{mM}$ CTAB/NaSal solution was compared to long rods using the software SANS Fit (developed at PSI). For $t=1 \mathrm{~min}$, the solution is formed mostly of cylinders (approximation to wormlike micelles) of 1,600 $\AA$ in length and $44 \AA$ in diameter and under flow conditions generates a clear anisotropic pattern. When $t=$ $500 \mathrm{~min}, 70 \%$ of the initial solution has already gone trough a transition to globular spheres of $70 \AA \AA$ in diameter, causing a drop in viscosity (see Fig. 14).

Figure $15 \mathrm{c}$ shows the same experiment using the S05 tubing, which had shown no significant weight loss. No
Fig. 15 a Flow cell used for SANS. The square shows the position where the patterns were obtained at the entrance of a planar contraction $(16: 2 \mathrm{~mm})$ with a gap (y-axis) of $1 \mathrm{~mm}$. The images on the right show the SANS scattering patterns as a function of time of the equimolar $10 \mathrm{mM}$ CTAB/NaSal solution under a volumetric flow rate of $0.09 \mathrm{~cm}^{3} / \mathrm{s}$ in contact with b S03; and c S05

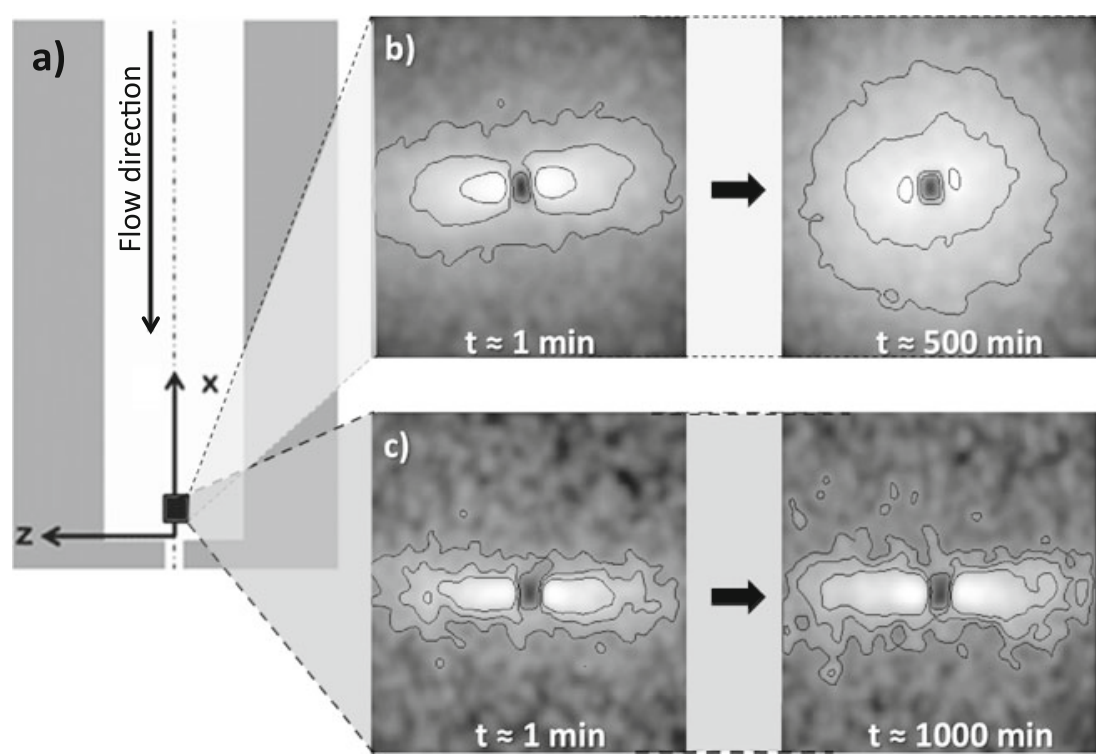


micellar degradation was observed after 1,000 min of circulation. Also, at higher volumetric flow rates and for longer times, no degradation was detected in this system, even after 2 days of circulation. The solution maintained its rheological properties and the wormlike structure. The fitting of the scattering curves with long cylinder models showed that even after long shearing periods, $100 \%$ of the curve could be related to cylinders with the same dimensions as described before.

\section{Conclusion}

The rheological and birefringence properties of dilute and semi-dilute equimolar cetyltrimethylammonium bromide and sodium salicylate solutions are investigated. The sweep direction for dilute $\mathrm{CTAB} / \mathrm{NaSal}$ solutions is of importance and results in different rheological responses. With increasing shear stress $(0.01-10 \mathrm{~Pa})$, shear thickening is measured for all concentrations. If the stress sweep decreases (10$0.01 \mathrm{~Pa}$ ), temporal shear oscillations are measured for concentrations lower than $10 \mathrm{mM}$ and at shear rates lower than $10 \mathrm{~s}^{-1}$. As a consequence, hysteresis areas are formed by the different sweep modes. These areas decrease with the concentration until they vanish in the semi-dilute regime. The critical shear stresses for the onset of the shear-thickening and the critical value for the stress oscillations exhibit a linear relation with concentration. Between both critical shear stresses, the system oscillates and does not achieve an equilibrium state, since it is composed of two different phases with diverse rheological properties. The frequency of these periodic oscillations increases with concentration, while their amplitude decreases.

The geometry of the flow cell as well as the gap size influences the formation of the temporal shear oscillation and shear-thickened phase. Measurements of the direct flow birefringence of dilute and semi-dilute solutions under different spatial confinement show shear-induced structures not assembling in bandlike structures as seen for other semidiluted surfactant solutions. The fact that the shear-aligned structure increases the viscosity in a shear-thickened transition and generates oscillations and, on the other hand, decreases the viscosity is not well understood up to now.

Degradation of wormlike solutions can happen by the transition to spherical micelles or by breaking down the micelles into shorter ones. Solutions exposed to rubber tubing were found in some cases to alter the wormlike micelles, but polyolefin tubing without plasticizer/lubricants was found to have no impact on structure formation, even after hours of contact under shear. Further studies of this sample are needed to understand why there was no interaction with the surfactant, nor any solubilization of hydrocarbons, and why the rheological properties of the solution remained unchanged.
Acknowledgements VLB acknowledges financial support by ETH Zurich and PSI as well as SANS measurements time. This work is also a collaboration with the Erasmus Mundus MaMaSELF program (Master in Materials Science Exploiting Large Scale Facilitiesmamaself.eu) with the grant number 2010-0138.

\section{References}

Aradian A, Cates ME (2006) Minimal model for chaotic shear banding in shear thickening fluids. Phys Rev E 73:041508

Azzouzzi H, Decruppe JP, Lerouge S, Greffier O (2005) Temporal oscillations of the shear stress and scattered light in a shearbanding-shear-thickening micellar solution. Eur Phys J E 17:507

Britton MM, Callaghan PT (1997) Two-phase shear band structures at uniform stress. Phys Rev Lett 78(26):4930

Britton MM, Callaghan PT (1999) Shear banding instability in wormlike micellar solutions. Eur Phys J B 7:237

Cates ME (1987) Reptation of living polymers: dynamics of entangled polymers in the presence of reversible chain-scission reactions. Macromeolecules 20:2289

Cates ME, Candau SJ (1990) Statics and dynamics of worm-like surfactant micelles. J Phys, Condens Matter 2:6869

Cates ME, Candau SJ (2001) Ring-driven shear thickening in wormlike micelles? Europhys Lett 55(6):887

Cates ME, McLeich TCB, Marrucci G (1993) The rheology of entangled polymers at very high shear rates. Europhys Lett 21(4):451

Dhont JKG, Briels WJ (2008) Gradient and vorticity banding. Rheol Acta 47:257

Ewoldt RH, McKinley GH (2007) Creep ringing in rheometry or how to deal with oft-discarded data in step stress tests. Rheol Bull 76(1):4-6

Ezrahi S, Tuval E, Aserin A (2006) Properties, main applications and perspectives of worm micelles. Adv Colloid Interface Sci 128130:77

Fischer P (2000) Time dependent flow in equimolar micellar solutions: transient behavior of the shear stress and first normal stress difference in shear induced structures coupled with flow instabilities. Rheol Acta 39:234

Fischer P, Rehage H (1997) Non-linear flow properties of viscoelastic surfactant solutions. Rheol Acta 36:13

Fischer P, Wheeler EK, Fuller GG (2002) Shear-banding structure orientated in the vorticity direction observed for equimolar micellar solution. Rheol Acta 41:35

Fischer P, Ouriev B, Windhab EJ (2009) Macroscopic pipe flow of micellar solutions investigated by Ultrasound Doppler velocimetry. Tenside Surfactants Deterg 46:140

Frank M, Anderson D, Weeks ER, Morris JF (2003) Particle migration in pressure-driven flow of a Brownian suspension. J Fluid Mech 493:363

Gamboa C, Sepulveda L (1986) High viscosities of cationic and anionic micellar solutions in the presence of added salt. J Colloid Interface Sci 113(2):566

Goymann CCM (2004) Physicochemical characterization of colloidal drug delivery systems such as reverse micelles, vesicles, liquid crystals and nanoparticles for topical administration. Eur J Pharm Biopharm 58:343

Hadri F, Guillou S (2010) Drag reduction by surfactant in closed turbulent flow. Int J Eng Sci Technol 2(12):6876

Hartmann V, Cressely R (1997a) Influence of sodium salicylate on the rheological behavior of an aqueous CTAB solution. Colloids Surf, A Physicochem Eng Asp 121:151

Hartmann V, Cressely R (1997b) Simple salts effects on the characteristics of the shear thickening exhibited by an aqueous micellar solution of CTAB/NaSal. Europhys Lett 40(6):691 
Helgeson ME, Vazquez PA, Kaler EW, Wagner NJ (2009a) Rheology and spatially resolved structure of cetyltrimethylammonium bromide wormlike micelles through the shear banding transition. $\mathbf{J}$ Rheol 53(3):727

Helgeson ME, Reichert MD, Hu YT, Wagner NJ (2009b) Relating shear banding, structure, and phase behavior in wormlike micellar solutions. Soft Matter 5:3858

Herle V, Fischer P, Windhab EJ (2005) Stress driven shear bands and the effect of confinement on their structures: a rheological, flow visualization, and rheo-SALS study. Langmuir 21:9051

Herle V, Kohlbrecher J, Pfister B, Fischer P, Windhab EJ (2007) Alternating vorticity bands in a solution of wormlike micelle. Phys Rev Lett 99:158302

Herle V, Manneville S, Fischer P (2008) Ultrasound velocimetry in a shear-thickening wormlike micellar solution: evidence for the coexistence of radial and vorticity shear bands. Eur Phys J E 26:3

Hoffmann H, Ulbricht W (1989) Transition of rodlike to globular micelles by the solubilization of additives. J Colloid Interface Sci 129(2):388

Hofmann S, Rauscher A, Hoffmann H (1991) Shear induced micellar structures. J Phys Chem 95:153

Hu Y, Wang SQ, Jamieson AM (1993a) Kinetics studies of shear thickening micellar studies. J Colloid Interface Sci 156:31

Hu Y, Wang SQ, Jamieson AM (1993b) Rheological and flow birefringence studies of a shear-thickening complex fluid: a surfactant model system. J Rheol 37(3):531

Hu Y, Rajaram CV, Wang SQ, Jamieson AM (1994) Shear thickening behavior of a rheopectic micellar solution: salt effects. Langmuir 10:80

Hu Y, Matthys EF (1995) Characterization of micellar structure dynamics for a drag-reducing surfactant solution under shear: normal stress studies and flow geometry effects. Rheol Acta 34:450

Hu YT, Boltenhagen P, Pine DJ (1998a) Shear thickening in lowconcentration solutions of wormlike micelles. I. Direct visualization of transient behavior and phase transitions. J Rheol 42(5): 1185

Hu YT, Boltenhagen P, Matthys E, Pine DJ (1998b) Shear thickening in low-concentration solutions of wormlike micelles. II. Slip, fracture, and stability of the shear-induced phase. J Rheol 42(5):1209

ISO 1817 (2005) Rubber, vulcanized—determination of the effect of liquids, 4 th edn

Israelachvili JN (1985) Intermolecular and surface forces. Academic, London

KaIus J, Hoffmann H, Chen SH, Lindner P (1989) Small-angle neutron scattering experiments of micellar solutions under shear. J Phys Chem 93:4261

Kallus S, Willenbacher N, Kirsch S, Distler D, Neidhfer T, Wilhelm M, Spiess HW (2001) Characterization of polymer dispersions by Fourier transform rheology. Rheol Acta 40:552

Kim WJ, Yang SM (2000) Effects of sodium salicylate on the microstructure of an aqueous micellar solution and its rheological responses. J Colloid Interface Sci 232:225

Koch S, Schneider T, Kuter W (1998) The velocity field of dilute cationic surfactant solutions in a Couette-viscometer. J NonNewton Fluid Mech 78:47

Lin B, Mohanty S, McCormick AV, Davis HT (2003) Study of the effect of added salt on micellization of cetyltrimethylammonium bromide surfactant. In: Mesoscale phenomena in fluid systems, ACS symposium series, vol 861, pp 313-326

Liu CH, Pine DJ (1996) Shear-induced gelation and fracture in micellar solutions. Phys Rev Lett 77(10):2121
Mair RW, Callaghan PT (1996) Observation of shear banding in worm-like micelles by NMR velocity imaging. Europhys Lett 36 : 719

Marin-Santibanez BM, Perez-Gonzalez J, Vargas L, RodriguezGonzalez F, Huelsz G (2006) Rheometry-PIV of shear-thickening wormlike micelles. Langmuir 22:4015

Miller E, Rothstein JP (2007) Transient evolution of shear-banding wormlike micellar solutions. J Non-Newton Fluid Mech 143:22

Mohanty S, Davis HT, McCormick AV (2001) Complementary use of simulations and free energy models for $\mathrm{CTAB} / \mathrm{NaSal}$ systems. Langmuir 17:7160

Normand V, Ravey JC (1997) Dynamic study of gelatin gels by creep measurements. Rheol Acta 36:610

Olmsted PD (2008) Perspectives on shear banding in complex fluids. Rheol Acta 47:283

Olmsted PD, Lu CYD (1997) Coexistence and phase separation in sheared complex fluids. Phys Rev E 56:55

Prötzl B, Springer J (1997) Light scattering experiments on shear induced structures of micellar solutions. J Colloid Interface Sci 190:327

Rehage H, Hoffmann H (1982) Shear induced phase transitions in highly dilute aqueous detergent solutions. Rheol Acta 21:561

Rehage H, Hoffmann H (1991) Viscoelastic surfactant solutions: model systems for rheological research. Mol Phys 74:933

Rehage H, Wunderlich I, Hoffmann H (1986) Shear induced phase transitions in dilute aqueous surfactant solutions. Colloid Polym Sci 72:51

Russel WB, Saville DA, Schowalter WR (1989) Colloidal dispersions. Cambridge University Press, Cambridge

Saito S, Mizuta Y (1967) Solubilization of polymers in aqueous cationic surfactant solution. J Colloid Interface Sci 23:604

Schweitzer PA (2006) Corrosion of polymer and elastomers. Taylor \& Francis, New York

Shikata T, Sakaiguchi Y, Uragami H, Tamura A, Hirata H (1987) Enormously elongated cationic surfactant micelle formed in CTABaromatic additive systems. J Colloid Interface Sci 119:291

Shikata T, Hirata H, Kotaka T (1988) Micelle formation of detergent molecules in aqueous media. 2. Role of free salicylate ions on viscoelastic properties of aqueous cetyltrimethylammonium bromide-sodium salicylate solutions. Langmuir 4(2):355

Shikata T, Hirata H, Kotaka T (1989) Micelle formation of detergent molecules in aqueous media. 3 . Viscoelastic properties of aqueous cetyltrimethylammonium bromide-salicylic acid solutions. Langmuir 5:398

Teixeira RE, Hazem PB, Shaqfeh ESG, Chu S (2005) Shear thinning and tumbling dynamics of single polymers in the flow-gradient plane. Macromolecules 38:581

Tripathi D (2002) Practical guide to polypropylene. Rapra Technology Limited, Shrewbury

Vasudevan M, Shen A, Khomami B, Sureshkumar R (2008) Selfsimilar shear thickening behavior in CTAB/NaSal surfactant solutions. J Rheol 52(2):527

Wilhelm M, Maring D, Spiess HW (1998) Fourier-transform rheology. Rheol Acta 37:399

Wilhelm M, Reinheimer P, Ortseifer M (1999) High sensitivity Fourier-transform rheology. Rheol Acta 38:349

Wheeler EK, Fischer P, Fuller GG (1998) Time-periodic flow induced structures and instabilities in a viscoelastic surfactant solution. J Non-Newton Fluid Mech 75:193

Wunderlich AM, Brunn PO (1989) The complex rheological behavior of an aqueous cationic surfactant solution investigated in a Couette-type viscometer. Colloid Polym Sci 267:627 